\title{
Optical study of thermally induced phase separation in evaporated $\mathrm{SiO}_{\mathbf{x}}$ films
}

\author{
I.Z. Indutnyy, I.P. Lisovskyy, D.O. Mazunov, P.E. Shepeliavyi, G.Yu. Rudko, V.A. Dan'ko \\ V. Lashkaryov Institute of Semiconductor Physics of National Academy of Sciences of Ukraine \\ 41, prospect Nauky, 03028 Kyiv, Ukraine \\ Phone: +380 (44)26563 42, fax: +380 (44) 26583 42; E-mail: indutnyy@isp.kiev.ua
}

\begin{abstract}
SiO}_{\mathrm{x}}$ thin films $(x \approx 1.3)$ have been prepared by thermal vacuum evaporation of silicon monoxide. A thermally stimulated (annealling temperatures -700 and $1000^{\circ} \mathrm{C}$ ) structural transformation of the $\mathrm{Si}-\mathrm{O}$ phase in the $\mathrm{SiO}_{\mathrm{x}}$ layers, which leads to the formation of amorphous and crystalline $\mathrm{Si}$ nanoinclusions, was investigated using photoluminescence and infrared spectroscopy. It is demonstrated that the heat treatment leads to the decomposition of molecular complexes of slightly oxidized Si and the formation of both Si clusters and molecular clusters containing heavily oxidized $\mathrm{Si}$. The transformations of the oxide phase are almost completed after $5 \mathrm{~min}$. of the thermal treatment. The films annealed at $700^{\circ} \mathrm{C}$ contain amorphous $\mathrm{Si}$ nanoclusters embedded into homogeneous $\mathrm{SiO}_{1.75}$ matrix (the volume share of amorphous $\mathrm{Si}$ phase is equal to $\sim 17$ vol.\%). The films annealed at $1000^{\circ} \mathrm{C}$ represent $\mathrm{Si}$ nanocrystals (the volume share is equal to $\sim 20$ vol.\%) surrounded by $\mathrm{SiO}_{\mathrm{x}}$ interface layers and embedded into $\mathrm{SiO}_{2}$. Both types of samples - the ones with $\mathrm{Si}$ nanocrystals and with amorphous Si nanoinclusions - exhibit photoluminescence in visible and near infrared spectral range. PL peak is blueshifted and is 5 to 10 time more intense for amorphous as compared with crystalline nano-Si. The origin of the light emission may be related to electron-hole pairs recombination in amorphous nanoinclusions and carrier recombination through double $\mathrm{Si}=\mathrm{O}$ bonds at the $n c-\mathrm{Si}-$ oxide matrix interface.
\end{abstract}

Keywords: nanocrystals, silicon oxide, photoluminescence.

Paper received 18.02.04; accepted for publication 17.06.04.

\section{Introduction}

Crystalline silicon is the basic material of the modern microelectronics. However, its use in optoelectronics is more modest because the efficiency of light emission in the visible range is very low due to the indirect band-gap electronic structure. Intensive investigations of light-emitting materials based on silicon started from 1990 when the visible photoluminescence of porous silicon was observed at room temperature [1]. Along with porous silicon, other structures with nanocrystalline silicon inclusions were developed and investigated, too. In particular, the composites that contain silicon nanocrystals $(n c-\mathrm{Si})$ in $\mathrm{SiO}_{2}\left(\right.$ or $\mathrm{SiO}_{\mathrm{x}}$ ) matrix have drawn attention of many researchers as possible materials for light emitting silicon-based structures. The advantages of $\mathrm{Si}_{-} \mathrm{SiO}_{2} \mathrm{com}$ posites, as compared with porous silicon, are the mechanical and chemical stability as well as process compatibility with modern silicon technology. The opportunities of the practical application of such structures in light-emitting diodes, lasers and optical amplifiers have already been shown.
The process of formation of such structures generally consists of two stages. First, $\mathrm{SiO}_{\mathrm{x}}$ films are produced either by thermal evaporation of silicon monoxide $(\mathrm{SiO})$ [2-5], implanting of $\mathrm{Si}$ atoms in $\mathrm{SiO}_{2}$ layers [6,7], chemical vapor deposition [8], or $\mathrm{Si}_{-} \mathrm{SiO}_{2}$ co-sputtering [9]. At the second stage, $\mathrm{SiO}_{\mathrm{x}}$ films are annealed, and the annealing leads to formation of Si clusters of nanometer sizes. The annealing temperature determines the structure of inclusions: annealing at 500 to $900^{\circ} \mathrm{C}$ favors the coagulation of Si atoms into amorphous clusters. At the annealing temperatures higher than $900^{\circ} \mathrm{C}$ the amorphous silicon inclusions start to crystallize, producing $n c-\mathrm{Si}$, electronic structure of which is modified by quantum confinement $[4,5]$. In principle, the emergence of such $\mathrm{Si}$ inclusions is in good agreement with the known phenomenon of $\mathrm{SiO}_{\mathrm{x}}$ matrix decomposition into $\mathrm{Si}$ and $\mathrm{SiO}_{2}$ phases at elevated temperatures [10,11]. Because of this circumstance, the investigation of structural-phase transformations of silicon oxides upon heating is of great importance from the viewpoint of understanding the mechanisms of Si nanoinclusion formation in the oxide matrix. 


\section{I.Z. Indutnyy et al.: Optical study of thermally induced phase separation in ...}

The method of light-emitting structures formation by vacuum thermal evaporation of $\mathrm{SiO}$ is very promising for the fabrication of large-area Si-based displays. The annealing-induced variations in characteristics of $\mathrm{SiO}_{\mathrm{x}}$ layers obtained by vacuum evaporation have been investigated in detail $[12,13]$. As a rule, the heat treatment was carried out in an oxidizing medium (usually in air). Specifically, the purpose was to obtain a wide set of films with a variable stoichiometry coefficient. However, such an approach does not permit one to keep track of the phase separation of the film material itself during thermal treatment. The reason is in additional oxidation of the film during the annealing. In the case of vacuum heat treatment or annealing in an inert atmosphere [3, 4], the prime attention was paid to the observation and characterization of the $\mathrm{Si}$ inclusions. At the same time, the analysis of the thermally stimulated changes in the structure and composition of $\mathrm{Si}-\mathrm{O}$ phase should give important additional information about the mechanism of formation of these inclusions.

In the present work, we carried out a detailed investigation of the variations in the structural properties of $\mathrm{SiO}_{\mathrm{x}}$ films as a result of heat treatment in inert atmosphere. The structural results were obtained from infrared spectroscopy and optical measurements. Photoluminescence (PL) experiments were also performed and interpreted together with the composition and the structure of the films.

\section{Experiment}

$\mathrm{SiO}_{\mathrm{x}}$ layers were obtained by thermal evaporation of $\mathrm{SiO}$ (Cerac Inc., purity of $99.9 \%$ ) in vacuum at the residual pressure of $2 \cdot 10^{-3} \mathrm{~Pa}$. Two-sided polished Si wafers and silica plates were used as substrates. The substrate temperature during deposition, was $150^{\circ} \mathrm{C}$. The film thickness $(d)$ was varied within the range of $150-350 \mathrm{~nm}$ to eliminate interference effects in PL measurements. $\mathrm{SiO}_{\mathrm{x}}$ layer composition depends on the deposition rate and residual pressure in vacuum chamber [14]. Our layers were deposited at the rate of $1.6 \mathrm{~nm} / \mathrm{s}$, the thickness being monitored in situ by the quartz-crystal-oscillator monitor system (KIT-1). After deposition, it was measured with the MII-4 microinterferometer. Some samples were annealed at 700 and $1000^{\circ} \mathrm{C}$ in $\mathrm{Ar}$ atmosphere during 5-30 $\mathrm{min}$. to obtain amorphous and crystalline inclusions in the oxide matrix [4].

Infrared (IR) transmission spectra were measured in the range of $800-1400 \mathrm{~cm}^{-1}$ using IKS-25M automated spectrometer. A Si substrate without an oxide film was used as a reference sample. It is known that the main absorption band for $\mathrm{SiO}_{\mathrm{x}}$, which corresponds to the assymmetric stretching vibration of the oxigen atom in its twofold coordinated bridging bonding site lies within the aforementioned range, and the position of the peak varies within the wavenumber range of $1000-1100 \mathrm{~cm}^{-1}$. This band was deconvolved into Gaussian profiles, main characteristics of which, specifically, positions and intensities of peaks, were analyzed in the context of the random bonding model. The purpose of the analysis was to determine the content of $\mathrm{Si}-\mathrm{O}_{\mathrm{y}}-\mathrm{Si}_{4-\mathrm{y}}(1 \leq y \leq 4)$ molecular complexes in the structural network of $\mathrm{SiO}_{\mathrm{x}}$ matrix according to the approach that was previously suggested [15]. The accuracy of the deconvolution procedure was characterized by the standard deviation of the Gaussian sum from the experimental curve. In our experiments, this deviation did not exceed $10^{-2}$.

The photoluminescence spectra were measured within the wavelength range of $600-1000 \mathrm{~nm}$ at room temperature using MDR grating spectrometer with cooled FEU62 photomultiplier and lock-in registration system. The $488 \mathrm{~nm}$ line of an $\mathrm{Ar}^{+}$-laser was used for excitation. The transmittance and reflectance spectra in the visible and near-infrared range were recorded at normal incidence using the KSVU-23 spectrophotometer at room temperature.

\section{Results and discussion}

\subsection{Infrared absorption results}

Figure 1 shows the transmittance spectra of the as-grown (curve 1) and annealed in Ar atmosphere at $700^{\circ} \mathrm{C}$ (curve 2) and $1000^{\circ} \mathrm{C}$ (curve 3 ) $\mathrm{SiO}_{\mathrm{x}}$ films. It can be seen that the fundamental absorption band for the annealed oxides noticeably shifts to higher frequencies (the peak position is 1022,1065 and $1075 \mathrm{~cm}^{-1}$ for the as-evaporated sample and for those annealed at 700 and $1000^{\circ} \mathrm{C}$, correspondingly), and its shape drastically changes. But this effect did not depend on the duration of the annealing: the variation of the annealing time from 5 to 30 minutes both at $700^{\circ} \mathrm{C}$ and at $1000^{\circ} \mathrm{C}$ results in the same changes of absorption spectra. This result evidences that the process of the oxide phase transformation takes place at the very beginning (less than $5 \mathrm{~min}$.) of the thermal treatment in accordance with the data on $n c$-Si formation in $\mathrm{SiO}_{2}$ films with implanted silicon $[7,16]$.



Fig. 1. IR transmittance spectra of $\mathrm{SiO}_{\mathrm{x}}$ films: as-evaporated (1), annealed at $700^{\circ} \mathrm{C}$ (2) and annealed at $1000^{\circ} \mathrm{C}$ (3) 


\section{I.Z. Indutnyy et al.: Optical study of thermally induced phase separation in ...}

The shift of the peak position of the Si-O-Si stretching mode is usually attributed to the variation in the phase composition of an oxide film [10, 12]. Moreover, using the position of the transmission-band peak $v_{M}$ and the known experimental data of the $v_{M}$ dependence on $x$ obtained for the oxides grown using the same technology $[12,17]$, we can estimate the oxide composition. This estimation demonstrates that, for $\mathrm{SiO}_{\mathrm{x}}$ films investigated, $x \approx 1.25,1.75$, and 1.91 prior to and after the heat treatments at $700^{\circ} \mathrm{C}$ and $1000^{\circ} \mathrm{C}$, respectively. Pai et al. [18] have proposed a linear relation between the peak frequency of the $\mathrm{Si}-\mathrm{O}$ infrared absorption band and the stoichiometry of the silicon oxide phase. Using their relation, we have obtained almost the same values of $x$ for our samples: 1.28, 1.81 and 1.94, respectively.

As is known, the optical absorption edge of homogeneous $\mathrm{SiO}_{\mathrm{x}}$ films monotonously shifts with the increase of $x$ from near IR for silicon up to ultraviolet for $\mathrm{SiO}_{2}$. The value of $x$ can be estimated (similarly to the paper [14]) using a theoretical or experimental dependence $E_{04}(x)$ [19], where $E_{04}$ is the energy at which the absorption coefficient is equal to $10^{4} \mathrm{~cm}^{-1}$. Using the measured absorption spectra we obtained $x=1.32 \pm 0.03$ for our as-evaporated samples. This value is a little higher than that obtained from IR measurements. The values of $x$ obtained for the as-deposited films imply that during the thermal deposition $\mathrm{SiO}$ clusters are partially oxidized due to the presence of oxygen in residual gases. Further variation of the phase composition of a film during the heat treatment in inert atmosphere proceeds due to the partial decomposition of $\mathrm{SiO}_{\mathrm{x}}$ into the mixture of $\mathrm{Si}$ and $\mathrm{SiO}_{2}$ (or $\left.\mathrm{SiO}_{\mathrm{y}}, y>x\right)$ phases $[4,10]$. This leads to an increase in the effective value of the stoichiometry index.

It must be pointed out that while the degree of structural transformation does not depend on the annealing time it does depend on the annealing temperature: at higher temperatures the volume fraction of the precipitated $\mathrm{Si}$ is larger and composition of a matrix becomes more similar to $\mathrm{SiO}_{2}$. However, even for the samples annealed at $1000^{\circ} \mathrm{C} x$ is less than 2 . It means that the decomposition of the oxide may be described by the equation: $y \mathrm{SiO}_{\mathrm{x}} \rightarrow(y-x) \mathrm{Si}+x \mathrm{SiO}_{\mathrm{y}}$, where $\mathrm{SiO}_{\mathrm{y}}$, probably, consists of $\mathrm{SiO}_{2}$ and $\mathrm{SiO}_{\mathrm{x}}$. The as-deposited films are highly homogeneous, no $a-\mathrm{Si}$ and $c-\mathrm{Si}$ domains are detected by Raman experiments [3, 4]. Alternatively, the atomic structure of the annealed films can be described as amorphous $\left(700^{\circ} \mathrm{C}\right)$ or crystalline $\left(1000^{\circ} \mathrm{C}\right)$ silicon clusters embedded into $\mathrm{SiO}_{\mathrm{y}}$ matrix [4]. Using the known molecular weights and densities of the components formed and taking into account the coefficients in the reaction equation, we can easily find the volume shares $v_{\mathrm{Si}}$ of $\mathrm{Si}$ phase formed: $v_{\mathrm{Si}}=17 \mathrm{vol} . \%$ of amorphous nanoclusters in the $\mathrm{SiO}_{1.75}$ matrix, $v_{\mathrm{Si}}=20$ vol. $\%$ of $n c-\mathrm{Si}$ in $\mathrm{SiO}_{1.91}$ matrix.

The analysis of the shape of the main IR-absorption band can give more detailed information on the process of the thermostimulated oxide phase transformation. For homogenous $\mathrm{SiO}_{\mathrm{x}}$ phase such an analysis has been carried out earlier [15] and gave results which were not discrepant with Random Bonding Model (RBM) statistic.
This approach was used here for as-evaporated samples. However, deconvolution of the absorption band into Gaussian profiles is rather problematic in the case of the annealed films. In fact, phase separation at elevated temperatures may, in principle, lead to the creation of the mixture of $\mathrm{SiO}_{2}$ and $\mathrm{SiO}_{\mathrm{x}}$ with different $x$ values. Hence, the shape analysis of the fundamental absorption band of annealed films should be performed using the known data for $\mathrm{SiO}_{2}$ and $\mathrm{SiO}_{\mathrm{x}}$ phases $[15,20]$ in the framework of three approaches: (1) homogenous $\mathrm{SiO}_{x}$ phase; (2) homogenous $\mathrm{SiO}_{2}$ phase; (3) mixture of $\mathrm{SiO}_{\mathrm{x}}$ and $\mathrm{SiO}_{2}$ phases. It should be noted that the absorption band of the films annealed at $700^{\circ} \mathrm{C}$ can not be fitted by the sum of Gaussians that are characteristic for $\mathrm{SiO}_{2}$ phase, hence, these films are $\mathrm{SiO}_{x}$ or mixture of $\mathrm{SiO}_{\mathrm{x}}$ and $\mathrm{SiO}_{2}$. Contrary to this result, the absorption band of the films annealed at $1000^{\circ} \mathrm{C}$ may be described with practically the same accuracy by the sum of Gaussians characteristic both for $\mathrm{SiO}_{2}, \mathrm{SiO}_{\mathrm{x}}$ phases and for their mixture. Hence, the question on the structure of these films remains open. To further analyse the composition and structure of the annealed oxides, we treated the samples in the 5\% solution of HF. Such solution can etch $\mathrm{SiO}_{2}$ phase and does not dissolve $\mathrm{SiO}_{\mathrm{x}}$. The oxide film, annealed at $700^{\circ} \mathrm{C}$ remained unchanged after 10 minutes of etching contrary to the film annealed at $1000^{\circ} \mathrm{C}$, which was etched with the rate of $20 \mathrm{~nm} / \mathrm{min}$. The control film of thermal $\mathrm{SiO}_{2}$ was etched with the rate of $50 \mathrm{~nm} / \mathrm{min}$. This experiment enables one to conclude that the oxide phase in the films annealed at $700^{\circ} \mathrm{C}$ may be most likely described as a homogeneous $\mathrm{SiO}_{\mathrm{x}}$, with $x$ larger than that for as-evaporated sample.

The oxide phase in the samples annealed at $1000^{\circ} \mathrm{C}$ consists of $\mathrm{SiO}_{2}$, or a mixture of $\mathrm{SiO}_{\mathrm{x}}$ and $\mathrm{SiO}_{2}$. Taking into account that these samples contain Si nanocrystals and a transition layer (with a composition of nonstoichiometric oxide) should exist between oxide phase and silicon inclusion [21], one can finally conclude that, after the treatment at $1000^{\circ} \mathrm{C}$, the oxide phase becomes most likely $\mathrm{SiO}_{2}$ with $\mathrm{SiO}_{\mathrm{x}}$ inclusions that cover $\mathrm{Si}$ nanocrystalls. Such inclusions should diminish the rate of the etching in fluorine acid as compared with pure $\mathrm{SiO}_{2}$ phase in thermal silicon dioxide.

Taking into account the above considerations, we have carried out deconvolution of the absorbance curves into Gaussian profiles. The parameters of the elementary Gaussian components obtained are presented in Table 1.

It can be seen that the main absorption band of oxide is mainly represented by the sum of eight profiles related to the stretching vibrations of bridging $\mathrm{O}$ atoms [15, 22]. Transverse and longitudinal vibrations correspond to the bands $1-5$ and $6-8$, respectively $[15,23]$. The week band related to $\mathrm{SiOH}$ complexes with the maximum position equal to $955 \mathrm{~cm}^{-1}$ [24] is not listed in the table. This band is observed in the spectrum of the as-deposited film only, and its contribution to the total bands area is $2.7 \%$. The ratio of LO and TO modes (ratio of the total area of LO bands to that of TO bands) increases from 0.28 for asdeposited films to 0.64 and 1.04 for the films annealed at 
I.Z. Indutnyy et al.: Optical study of thermally induced phase separation in ...

Table 1. Parameters of the elementary absorption bands

\begin{tabular}{|c|c|c|c|c|c|c|}
\hline \multirow[t]{2}{*}{ Band } & \multirow{2}{*}{$\begin{array}{l}\text { Maximum } \\
\text { position } \\
\left(\mathrm{cm}^{-1}\right)\end{array}$} & \multirow[t]{2}{*}{$\begin{array}{l}\text { Mode } \\
\text { type }\end{array}$} & \multirow{2}{*}{$\begin{array}{l}\text { Dominant } \\
\text { structural } \\
\text { component }\end{array}$} & \multicolumn{3}{|c|}{$\begin{array}{l}\text { Areas of bands (normalized to the total areas } \\
\text { of TO and LO modes, respectively), percents }\end{array}$} \\
\hline & & & & As-deposited & $\begin{array}{l}\text { Annealed } \\
\text { at } 700^{\circ} \mathrm{C}\end{array}$ & $\begin{array}{l}\text { Annealed } \\
\text { at } 1000^{\circ} \mathrm{C}\end{array}$ \\
\hline 1 & 1000 & TO & $\mathrm{SiOSi}_{3}$ & 22 & 11 & No Gaussian \\
\hline 2 & 1031 & TO & $\mathrm{SiO}_{2} \mathrm{Si}_{2}$ & 29 & 30 & 16 \\
\hline 3 & 1050 & TO & $\mathrm{SiO}_{4}$ & No Gaussian & No Gaussian & 31 \\
\hline 4 & 1067 & TO & $\mathrm{SiO}_{3} \mathrm{Si}$ & 27 & 32 & 18 \\
\hline 5 & 1095 & TO & $\mathrm{SiO}_{4}$ & 22 & 28 & 35 \\
\hline 6 & 1142 & $\mathrm{LO}$ & & 100 & 53 & 39 \\
\hline 7 & 1195 & $\mathrm{LO}$ & & No Gaussian & 47 & 38 \\
\hline 8 & 1233 & $\mathrm{LO}$ & & No Gaussian & No Gaussian & 23 \\
\hline
\end{tabular}

$700^{\circ} \mathrm{C}$ and $1000^{\circ} \mathrm{C}$, respectively. Thus, it is seen that the heat treatment of $\mathrm{SiO}_{\mathrm{x}}$ layers results in a substantial redistribution of elementary band intensities and affects on the ratio of TO and LO modes. The temperature seems to be the main factor in the processes under consideration.

Contribution of TO and LO modes into IR absorption is not equivalent: while the intensities of the transverse bands are mainly connected with the concentration of bridging oxygen atoms in the corresponding structural units (according to the RBM - molecular complexes $\mathrm{Si}-$ $\left.\mathrm{O}_{\mathrm{y}}-\mathrm{Si}_{4-\mathrm{y}}(1=y=4)\right)$, the intensities of the bands related to the longitudinal mode are strongly dependent on the matrix polarizability (i.e. on $x$ ), oxide homogeneity and on experimental conditions [25-27]. Thus, the transverse mode is more suitable for the analysis of the structural transformations of $\mathrm{SiO}_{\mathrm{x}}$ films. The content of each kind of molecular complexes in the oxide network can be estimated from the contribution of corresponding profiles to the total area of TO mode (these values are listed in the last three columns of the Table 1). It is seen that the contribution of the band ascribed to the $\mathrm{SiOSi}_{3}$ complexes substantially decreases after the annealing at $700^{\circ} \mathrm{C}$ and disappears after the treatment at $1000^{\circ} \mathrm{C}$. Alternatively, the fraction of the vibrations determined by the bridging $\mathrm{O}$ atoms, which appear in $\mathrm{SiO}_{4}$ complexes, increases with temperature. At the annealing at $1000^{\circ} \mathrm{C}$ the relative area of the bands related to $\mathrm{SiO}_{4}$ tetrahedra increases by 3 times as compared with the as-deposited film. In the films annealed at $700^{\circ} \mathrm{C}$, the contribution of the band related to $\mathrm{SiO}_{2} \mathrm{Si}_{2}$ remains practically unchanged, but the relative area of the bands ascribed to $\mathrm{SiO}_{3} \mathrm{Si}$ and $\mathrm{SiO}_{4}$ clusters increases. These facts can imply that the heat treatment of $\mathrm{SiO}_{\mathrm{x}}$ causes the decomposition of molecular complexes of slightly oxidized Si and the formation of both $\mathrm{Si}$ clusters and clusters containing heavily oxidized $\mathrm{Si}$.

It seems natural that the contributions of $\mathrm{SiO}_{2} \mathrm{Si}_{2}$ and $\mathrm{SiO}_{3} \mathrm{Si}$ complexes substantially decrease after the heat treatment at $1000^{\circ} \mathrm{C}$. In fact, to create $\mathrm{SiO}_{4}$ tetrahedra the oxygen atoms (which are released from $\mathrm{SiOSi}_{3}$ com- plexes) have to react with another silicon-oxygen units. Such units can be only $\mathrm{SiO}_{2} \mathrm{Si}_{2}$ and $\mathrm{SiO}_{3} \mathrm{Si}$ clusters. Some of these clusters that remain in the oxide matrix most likely belong to the interface $\mathrm{SiO}_{\mathrm{x}}$ layers between $\mathrm{Si}$ nanocrystalls and $\mathrm{SiO}_{2}$ phase. We can estimate the volume share of this interfacial phase for the samples annealed at $1000^{\circ} \mathrm{C}$. According to [21], the thickness of the interface Si-rich suboxide layers is equal to $0.4-0.6 \mathrm{~nm}$. Assuming the average diameter of spherical Si nanocrystalls to be equal to $3 \mathrm{~nm}$ (see the next clause) and using $v_{\mathrm{Si}}$ value, we can obtain the volume share of $\mathrm{SiO}_{\mathrm{x}}$ phase: $v_{\mathrm{SiO}_{\mathrm{x}}}=21 \ldots 35 \mathrm{vol} . \%$. These values are in accordance with the contribution of the bands assigned to $\mathrm{SiO}_{2} \mathrm{Si}_{2}$ and $\mathrm{SiO}_{3} \mathrm{Si}$ clusters into the total area of the TO mode and reach $34 \%$ (see Table 1 ).

It is well known [28] that in silicon dioxide network $\mathrm{SiO}_{4}$ tetrahedra are incorporated into the rings of different kinds, the 4- and 6-folded ones being the most probable. The value of Si-O-Si bond angles $(\theta)$ depends on the ring type: $\theta \sim 144^{\circ}$ and $\theta \sim 130^{\circ}$ are inherent to the 6fold and 4-fold rings, respectively [15, 28]. The bands 3 and 5 (see Table 1) in the case of $\mathrm{SiO}_{2}$ lattice correspond to the vibrations of bridging oxygen atoms with $\mathrm{Si}-\mathrm{O}-\mathrm{Si}$ bond angles $\theta \sim 130^{\circ}$ and $\theta \sim 144^{\circ}$, respectively [15]. In other words, when $\mathrm{SiO}_{2}$ phase is already formed the area of these bands reflects the content of 4- and 6-fold $\mathrm{SiO}_{4}$ tetrahedra rings. It was established earlier [29] that the areas of the above mentioned bands depend on the thickness of the silicon dioxide film, because the 4-fold $\mathrm{SiO}_{4}$ tetrahedra rings dominate in the lattice of ultra-thin films. The ratio value of Gaussians 3 and 5 areas in our case is close to 1 (see Table 1). Taking into account that the band 5 corresponds to $\mathrm{SiO}_{4}$ tetrahedra both in $\mathrm{SiO}_{2}$ phase and in $\mathrm{SiO}_{\mathrm{x}}$ phase of the transition layers, one can expect that for $\mathrm{SiO}_{2}$ phase this value should be remarkably larger than 1 . Such value is inherent to ultrathin (thinner than $20 \mathrm{~nm}$ ) silicon dioxide films [20, 29].

Thus, summing all mentioned above, we may conclude that the films annealed at $1000^{\circ} \mathrm{C}$ represent Si nano- 


\section{I.Z. Indutnyy et al.: Optical study of thermally induced phase separation in ...}

crystalls surrounded by $\mathrm{SiO}_{\mathrm{x}}$ interface layers and embedded into $\mathrm{SiO}_{2}$. The structure of $\mathrm{SiO}_{2}$ phase coincides with the structure of ultrathin $\mathrm{SiO}_{2}$ films. Alternatively, the samples, annealed at $700^{\circ} \mathrm{C}$ contain amorphous Si nanoclusters embedded into homogeneous $\mathrm{SiO}_{1.75}$ matrix.

A substantial increase in the intensity of the bands of longitudinal optical (LO) phonons due to the heat treatment was observed previously $[3,13]$. This effect may be associated with the heterogeneity of the annealed film due to formation of the phases of variable composition.

\subsection{Photoluminescence measurements}

The as-evaporated $\mathrm{SiO}_{\mathrm{x}}$ films show rather weak photoluminescence in the visible range. After the annealing at $700^{\circ} \mathrm{C}$ for $5 \mathrm{~min}$., an intense band appears in PL spectrum centered around $785 \mathrm{~nm}$ (Fig. 2, curve 1). The increase of the annealling time up to $30 \mathrm{~min}$ (Fig. 2, curve 2) results in a small shift of this PL peak to longer wavelengths by $10 \mathrm{~nm}$ without noticeable change in the intensity and half width $(240 \mathrm{~nm})$.

Fig. 3 shows room-temperature PL spectra obtained for $\mathrm{SiO}_{\mathrm{x}}$ films annealed at $1000^{\circ} \mathrm{C}$ for $5 \mathrm{~min}$. (curve 1) and $30 \mathrm{~min}$. (curve 2). Both annealed samples are characterized by a broad PL band (with the half width about $200 \mathrm{~nm}$ ) that ranges from $650 \mathrm{~nm}$ to beyond $980 \mathrm{~nm}$. According to [5], this band corresponds to the emission from nanocrystals with the diameter of $2 \mathrm{~nm}$ or larger. An increase in the annealing duration leads to the twofold increase in PL intensity, in accordance with the previous results [4]. At the same time, the peak position of this PL band remains almost unchanged $(860 \mathrm{~nm}$ for $5 \mathrm{~min}$. annealing and $855 \mathrm{~nm}$ for $30 \mathrm{~min}$ ). PL peak position and its halfwidth value for our samples annealed at $1000^{\circ} \mathrm{C}$ are in agreement with the results of other authors $[5,7,30]$.

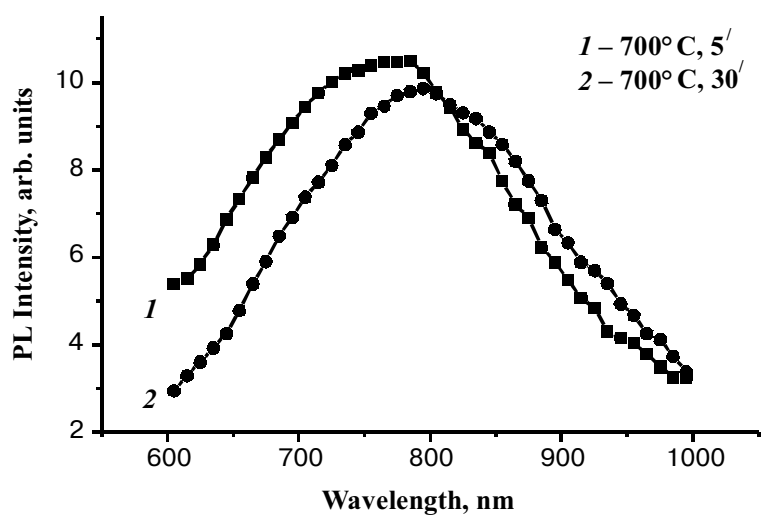

Fig. 2. $\mathrm{PL}$ spectra of $\mathrm{SiO}_{\mathrm{x}}$ films annealed at $700^{\circ} \mathrm{C}$ for $5 \mathrm{~min}$. (1) and $30 \mathrm{~min}$. (2).

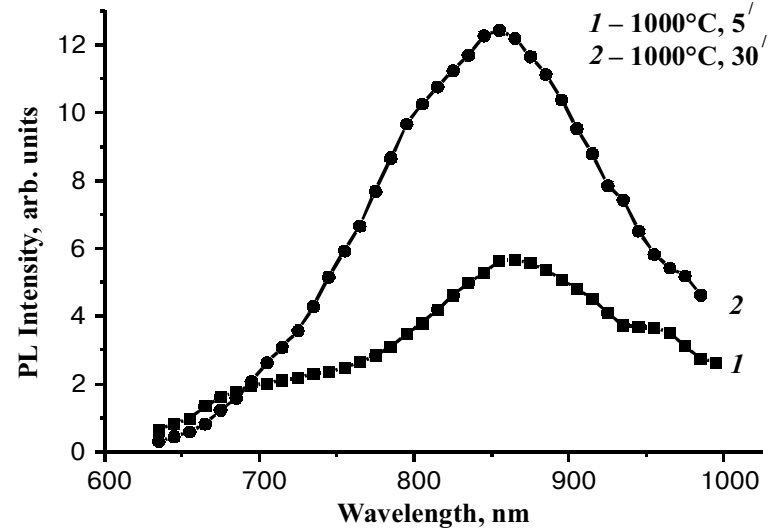

Fig. 3. PL spectra of $\mathrm{SiOx}$ films annealed at $1000^{\circ} \mathrm{C}$ for $5 \mathrm{~min}$. (1) and $30 \mathrm{~min}$. (2).

PL emission from the films annealed at $700^{\circ} \mathrm{C}$ is blueshifted and 5 to 10 times more intense as compared to $\mathrm{PL}$ from the samples annealed at $1000^{\circ} \mathrm{C}$.

Si nanocrystals in $\mathrm{SiO}_{\mathrm{x}}$ films annealed at high temperatures $\left(\geq 1000^{\circ} \mathrm{C}\right)$ were observed by different authors and the measurements of their size distribution were carried out using high resolution electron microscopy $[5,7$, 8]. It was shown that the average size of $n c$-Si depends on the silicon content in the as-prepared films. But there are diverse results concerning the average size of nanocrystals. For the films with $x=1.3$ (close to our case) and annealed at about $1000^{\circ} \mathrm{C}, \mathrm{Si}$ nanocrystals uniformly distributed in oxide matrix were observed and their mean diameter was $\sim 4.3 \mathrm{~nm}$ (thermally evaporated films) [5], $2 \mathrm{~nm}$ (films obtained by plasma enhanced chemical vapor deposition [30]), 3...3.5 nm (implanted $\mathrm{Si}_{-} \mathrm{SiO}_{2}$ layers) [7]. The estimation of the average $n c-\mathrm{Si}$ size in the thermally evaporated $\mathrm{SiO}_{\mathrm{x}}$ films of the same stoichiometry, using Raman spectra, has given the value about $2 \mathrm{~nm}$ [4].

As it was revealed in $[8,31]$, the size of the nanocrystals considerably increases with the annealing temperature and for $1250^{\circ} \mathrm{C}$ the average size is about $4 \mathrm{~nm}$. However, the time of annealing almost does not influence the size of nanocrystals; their average diameter increases very slowly, almost imperceptibly, when the annealing time changes from $1 \mathrm{~min}$. to $16 \mathrm{~h}[7,16]$. The same increasing in PL intensity with the time of annealing without noticeable changes in peak position was observed in Si implanted oxide layers [7, 16]. PL intensity have shown an inverse correlation with the amount of paramagnetic defect centers at $\mathrm{Si}_{-} \mathrm{SiO}_{2}$ nanocrystal matrix interfaces [7, 6]. The interpretation of such correlations is that $n c$-Si are formed during the first minutes of the annealing; for the rest of the annealing procedure their size does not increase and the PL intensity increases due to a reduction (passivation) of nonradiative recombination centers (interface defects). We suppose that this interpretation can be applied to our results obtained on the samples annealed at $1000^{\circ} \mathrm{C}$. 


\section{I.Z. Indutnyy et al.: Optical study of thermally induced phase separation in ...}

Alternative interpretations in literature are invoked to explain the origin of PL phenomenon in such materials. The photoluminescence could be attributed to silicon oxide defect centers, interface states between the silicon clusters and the silicon oxide matrix, or to recombination of confined electron-hole pairs within silicon nanoinclusions. But, as revealed in the previous paper [4], the intensity of PL band that is related to the defects in $\mathrm{SiO}_{\mathrm{x}}$ grows with the annealing temperature until it reaches $600^{\circ} \mathrm{C}$ and falls dramatically at higher temperatures. It testifies that PL emission observed in our samples is caused by a recombination of carriers within silicon inclusions, or on radiative interface states.

The experimentally observed correlation between the average size of the nanocrystals with PL emission energy shows that PL from $n c$-Si can be attributed to band-toband radiative recombination of electron-hole pairs confined within such nanoparticles [1]. But large Stokes shifts between absorption and emission in $n c$-Si structures and experiments on passivation of nonradiative states and defects by hydrogen have shown that the interface $n c-\mathrm{Si}$ oxide matrix does play an important role in emission mechanism of such structures. These experimental facts have been reconciled recently in the model that accounts for both size-dependence (in a limited range of $n c$-Si sizes) and role of interface states [32]. According to this model, PL emission results from the radiative recombination of electron-hole pairs trapped at the interfacial $\mathrm{Si}=\mathrm{O}$ double bonds. At present, this model gives the most complete description of the known experimental data (including our data on the samples annealed at $1000^{\circ} \mathrm{C}$ ).

The films annealed at $700^{\circ} \mathrm{C}$ contain amorphous silicon nanoparticles [4, 5], and intense PL has already been observed in such films [3, 5]. However, as the sizes of amorphous nanoparticles cannot be determined using Raman scattering measurements or high resolution electronic microscopy, interpretation of PL from oxide layers, containing amorphous inclusions, is still a matter of debate.

We do not know the size of amorphous silicon nanoclusters in our samples. However, one can assume that they are smaller than $n c$-Si in the layers which have been annealled at $1000^{\circ} \mathrm{C}$ because the size of crystals essentially decreases with the reduction of the annealing temperature (e.g., it is known that at $1250^{\circ} \mathrm{C}$ annealing the nanocrystals are twice as large as at $1100^{\circ} \mathrm{C}$ [31]). This can account for the short wavelength shift of the PL band in the samples annealed at $700^{\circ} \mathrm{C}$ as compared with those annealed at $1000^{\circ} \mathrm{C}$. According to our estimation, the volume fraction of amorphous silicon particles is smaller than that of the nanocrystals formed at $1000^{\circ} \mathrm{C}$ (17 and $20 \mathrm{vol} \%$, respectively). However, owing to the smaller sizes, their concentration is apparently higher. Higher concentration of small amorphous inclusions results in higher PL intensity in comparison with the layers containing $n c$-Si inclusions.

Small shift of PL peak position towards long wavelengths with the annealing time increase can be caused by a small increase of the average size of amorphous $\mathrm{Si}$ inclusions caused by coalescence of the smallest inclusions in larger ones without change of silicon and oxide volume fractions. We should remind that our IR measurements have shown that the structure of the oxide matrix does not change at the increase of the annealing time from 5 to 30 minutes. Thus, at $700^{\circ} \mathrm{C}$ (as well as at $1000^{\circ} \mathrm{C}$ ) the process of silicon and oxide phase stratification is finished within the first 5 minutes of heating.

Independence of PL intensity on the annealing time testifies that for amorphous Si inclusions the passivation of Si-oxide interface does not play as important role in the emission process as for $n c-\mathrm{Si}$. This result agrees with the paper [33] in which shown was that hydrogen does not greatly influence PL efficiency of amorphous Si clusters. All these results suggest that PL in our samples annealed at $700^{\circ} \mathrm{C}$ can be attributed to the recombination of the confined electron-hole pairs in amorphous silicon clusters embedded into $\mathrm{SiO}_{1.75}$ matrix.

\section{Conclusions}

Heat treatment of SiOx films deposited by thermal evaporation causes the structural changes and affects the physical properties of the film. The oxide phase transformations take place at the very beginning (less than $5 \mathrm{~min}$.) of the thermal treatment both at $700^{\circ}$ and $1000^{\circ} \mathrm{C}$. This treatment results in the decomposition of molecular complexes of slightly oxidized $\mathrm{Si}$ and in the formation of both $\mathrm{Si}$ inclusions and clusters containing heavily oxidized Si. The content of heavily oxidized clusters depends on the temperature of heat treatment.

The structure of the films annealed at $700^{\circ} \mathrm{C}$ can be described as amorphous Si nanoclusters embedded into homogeneous $\mathrm{SiO}_{\mathrm{x}}$, with $\mathrm{x}$ larger than that for the asevaporated sample. The films annealed at $1000^{\circ} \mathrm{C}$ contain $\mathrm{Si}$ nanocrystalls surrounded by $\mathrm{SiO}_{\mathrm{x}}$ interface layers and embedded into $\mathrm{SiO}_{2}$. The structure of $\mathrm{SiO}_{2}$ phase in these films coincides with that of ultrathin $\mathrm{SiO}_{2}$ films.

PL emission from the samples with $\mathrm{Si}$ amorphous nanoinclusions is blueshifted and 5 to 10 time more intense as compared with the emission from the samples with Si nanocrystals. This PL can be interpreted in terms of the electron-hole pairs recombination in amorphous nanoinclusions (the samples annealed at $700^{\circ} \mathrm{C}$ ) and at the double $\mathrm{Si}=\mathrm{O}$ bonds at the $n c-\mathrm{Si}$ - oxide matrix interface (the films annealed at $1000^{\circ} \mathrm{C}$ ).

\section{References}

1. L.T. Canham // Appl. Phys. Lett., 57, p. 1046 (1990).

2. I.P. Lisovskyy, I.Z. Indutnyy, B.N. Gnennyy et al. // Fiz. Tekh. Poluprovodn. (St. Petersburg), 37, p. 98 [Semiconductors 37(2003) 97] (2003).

3. H. Rinnert, M. Vergant, A. Burneau. // J. Appl. Phys., 89, p. 237 (2001).

4. V.Ya. Bratus', V.A. Yukhimchuk, L.I. Berezhinski et al. // Fiz. Tekh. Poluprovodn. (St. Petersburg), 35, p. 854 [Semiconductors 35(2001) 821] (2001).

5. D. Nesheva, C. Raptis, and A. Perakis, et al. // J. Appl. Phys., 92, p. 4678 (2002). 


\section{I.Z. Indutnyy et al.: Optical study of thermally induced phase separation in ...}

6. M.Ya. Valakh, V.A. Yukhimchuk, V.Ya. Bratus', et al. // $J$. Appl. Phys., 85, p. 168 (1999).

7. B.G. Fernandez, M. Lopez, C. Garcia, et al. // J. Appl. Phys., 91, p. 798 (2002).

8. F. Priolo, G. Franzo, D. Pacifici, et al. // J. Appl. Phys., 89 p. 264 (2001).

9. B. Gallas, C.-C. Kao, S. Fisson, et al. // Appl. Surf. Sci., $\mathbf{1 8 5}$ p. 317 (2002).

10. K. Hubner // Phys. Status Solidi, A61, p. 665 (1980).

11. F. Rochet, G. Dudour, H. Roulet, et al. // Phys. Rev. B, 37, p. 6468 (1988).

12. M. Nakamura, Y. Mochizuki, K. Usami, Y. Itoh, T. Nozaki. // Solid State Communications, 50, p. 1079 (1984).

13. L.I. Berezhinski, N.V. Sopinski, and V.S. Khomchenko // Zh. Prikl. Spektrosk., 68, p. 103 (2001)

14. A.L. Shabalov and M.S. Feldman // Thin Solid Films, 110, p. 215 (1983)

15. I.P. Lisovskyy, V.G. Litovchenko, V.B. Lozinskii, et al. // J. Non-Cryst. Solids, 187, p. 91, (1995).

16. M. Lopez, B. Garrido, C. Garcia et al. // Appl. Phys. Lett., 80, p. 1637 (2002).

17. A.L. Shabalov, M.S. Fel'dman, and M.Z. Bashirov // Izv. Akad. Nauk Az. SSR, No. 3, p. 78 (1986).

18. P.G. Pai, S.S. Chao, Y. Takagi, and G. Lucovsky // J. Vac. Sci. Technol., B4, p. 689 (1986).

19. G. Zuther // Phys. Stat. Sol. (a), 59, p. K109 (1980).

20. I.W. Boyd // Appl. Phys. Lett., 51, p. 418 (1987).
21. B.J. Hinds, F. Wang, D.M. Wolfe, et al. // J. Vac. Sci. Technol. $B$, 16, p. 2171 (1998).

22. I.P. Lisovskyy, V.G. Litovchenko, V.B. Lozinskii, V.P. Melnik, S.I. Frolov. // Thin Solid Films, 247, p. 264 (1994).

23. Y. Jia, Y. Liang, Y. Liu, D. Shen // Thin Solid Films, 370, p. 199 (2000)

24. V.A. Skryshevskii and V.P. Tolstoi, Infrared Spectroscopy of Semiconductor Structures, Lybid', Kiev (1991).

25. D.W. Berreman // Phys. Rev., 130, p. 2193 (1963).

26. A. Lehmann, L. Shumann, K. Hubner. // Phys. Stat. Sol. (b), 117, p. 689 (1983).

27. A. Lehmann, L. Shumann, K. Hubner. // Phys. Stat. Sol. (b), 121, p. 505 (1984).

28. I.P. Lisovskyy, V.G. Litovchenko, B.M. Gnenyy, W. Fussel, A.E. Kiv, V.N. Soloviev, T.I. Maximova // J. Mat. Sci.: Materials in electronics, 13, p. 167 (2002).

29. I.P. Lisovskyy, V.G. Litovchenko, V.B.Lozinskii, G.I. Steblovskii // Thin Solid Films, 213, p. 164 (1992).

30. M.L. Brongersma, A. Polman, K.S. Min, and H.A. Atwater // J. Appl.Phys., 86, p. 759 (1999).

31. G. Franzo, A. Irrera, E.C. Moreira et al. // Appl. Phys. A, 74, p. 1, (2002).

32. M.V. Wolkin, J. Jorne, P.M. Fauchet, et al. // Phys. Rev. Lett., 82, p. 197 (1999).

33. H. Rinnert, M. Vergnat, G. Marchal, and A. Burneau // Appl. Phys. Lett., 72, p. 3157 (1998). 